\section{P239 EFFECT OF INHALED CORTICOSTEROID (ICS) PARTICLE SIZE ON ASTHMA EFFICACY AND SAFETY OUTCOMES: A SYSTEMATIC LITERATURE REVIEW}

${ }^{1} E$ Suarez, ${ }^{1} S$ Fang, ${ }^{1} \mathrm{~J}$ Abraham, ${ }^{2} \mathrm{RL}$ DiSantostefano, ${ }^{2} \mathrm{DA}$ Stempel, ${ }^{2} \mathrm{~L}$ Frith, ${ }^{2} \mathrm{NC}$ Barnes. ${ }^{1}$ New England Research Institutes, Inc., Watertown, MA, USA; ${ }^{2}$ GlaxoSmithKline, Uxbridge, UK

\subsection{6/thoraxjnl-2014-206260.367}

Introduction and objectives ICS of differing particle size, due both to the formulation and propellant, may impact patient outcomes. This systematic review of randomised controlled trials compared asthma efficacy and safety outcomes from the use of fluticasone propionate (FP)-containing medications and alternative smaller particle ICS.

Methods English language published peer-reviewed literature (Jan 1, 1998-Feb 13, 2014) with FP-containing medications, yielded 1,655 potentially-relevant articles: 1,575 were excluded, 80 full-text articles were reviewed, and 25 were extracted for data with treatment comparisons (FP- vs. small particle ICS-containing medicines). Efficacy measures included lung function, asthma exacerbations, and rescue medication use. Safety endpoints included adverse events, growth and bone measures, and cortisol. Benefit-risk interval plots of risk differences with 95\% confidence intervals were produced for FP vs. comparators.

Results Ten controlled trials compared the efficacy of FP with beclomethasone diproprionate (BDP-HFA). Six studies found no appreciable differences in efficacy while four trials identified improvement in lung function with FP vs. BDP-HFA. In ten randomised trials comparing the efficacy of ciclesonide (CIC) with FP, CIC was found to be non-inferior or not statistically different from FP on numerous efficacy endpoints in the majority of the studies. Most safety assessments across nine trials did not differ between treatments. Results were similar for fixed dose combination therapies that contained FP and BDP-HFA ( $\mathrm{n}=3$ trials).

Conclusions This systematic review suggests no differences in efficacy or safety between FP-containing medications and small particle size ICS medications for the treatment of asthma.

(GSK-funded, LS2270)

\section{P240 SMARTINHALERS - A NEW APPROACH TO ASSESSING ADHERENCE IN DIFFICULT ASTHMA}

P Hall, M Bracken, D Winch, P Nagakumar, A Bush, S Saglani, L Fleming. Royal Brompton Hospital, London, UK

\subsection{6/thoraxjnl-2014-206260.368}

Introduction Poor adherence is one of the key determinants of sub-optimal asthma control in children. Correctly identifying children with poor adherence can avoid unnecessary escalation of treatment and enable a targeted adherence intervention.

Objective To use electronic monitoring devices (Smartinhalers) to measure adherence to inhaled corticosteroids (ICS) in children with problematic severe asthma (PSA) and compare the data with prescription uptake and symptoms during the monitoring period.

Methods Smartinhalers were issued to patients for a 6-8 week study period as part of an established nurse led assessment in a tertiary referral centre. Advice regarding adherence and the purpose of the Smartinhalers was explained to all children and their parents. Lung function, bronchodilator reversibility, exhaled nitric oxide (FENO), mini paediatric asthma quality of life questionnaire (mPAQLQ), and asthma control test (ACT) were recorded at baseline and follow up. Wilcoxon signed ranks was
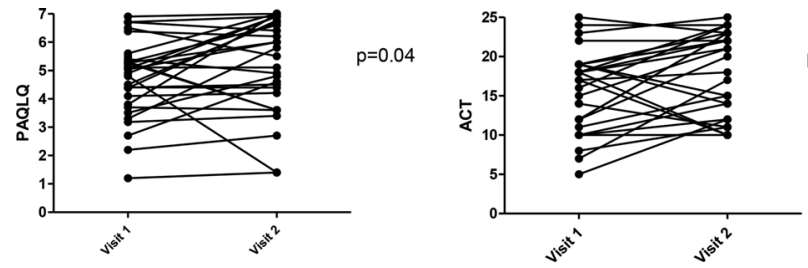

$p=0.02$

Abstract P240 Figure 1

used to compare visit 1 and visit 2 data. GP prescription uptake for ICS and number of salbutamol canisters issued in past year were obtained.

Results 33 children (21 male), median age 13 (5-17) years) were issued with Smartinhalers. 15 had adherence $>80 \%, 14$ between $50-80 \%$ and $4<50 \%$. ACT and mPAQLQ improved significantly over the monitoring period (Figures 1 and 2). Children with a prescription uptake of $<80 \%$ had a significant improvement in ACT compared to those with pick up of $\geq 80 \%$ (median change 3.5 (IQR 0.75-7.25) vs 0 (-4-3)) and a non-significant trend towards improvements in FEV1 and BDR.

There was no relationship between prescription uptake and Smartinhaler adherence or salbutamol inhalers collected.

Conclusion Even when children know they are being monitored over half used $<80 \%$ of the prescribed dose. Improvements in objective markers of asthma control during the monitoring period can help to identify those who were previously poorly adherent. Smartinhalers are useful tools in the assessment of adherence in conjunction with GP prescriptions and clinical observations.

\section{P241 ANTI-REFLUX SURGERY CONVEYS A LONG TERM IMPROVEMENT IN RESPIRATORY SYMPTOMS IN ASTHMA AND CHRONIC COUGH}

KE Cusworth, CA Lynch, S Ejiofor, R Sathyamurthy, P Super, C Noble, AH Mansur. Birmingham Heartlands Hospital, Birmingham, UK

\subsection{6/thoraxjnl-2014-206260.369}

Introduction Previously we have reported short term improvement in asthma related quality of life (AQLQ) and cough scores following anti-reflux surgery in asthma and chronic cough patients with gastro-oesophageal reflux disease (GORD) that did not respond to medical treatment. Herein we report on longterm outcome data.

Method A database of respiratory patients undergoing antireflux surgery was set up to assess GORD and respiratory symptoms at baseline, 3 months and long-term (mean 5 years). Data on lung function was also collected.

Results Twenty-eight patients ( $71 \%$ female, mean age $=50.1$ years) completed an AQLQ (13 asthmatics) or cough score questionnaire (15 chronic cough patients) at a mean of 66 months following surgery (range $=6-100$ months). The Hull reflux cough questionnaire (HRCQ) was also completed. All had significant reflux at baseline confirmed with oesophageal manometry and $\mathrm{pH}$ studies (mean DeMeester score of 47.26 [normal < 14.72], mean lower oesophageal sphincter pressure of $4.6 \mathrm{mmHg}$ [normal $=12-25]$ and a mean reflux time of $11.7 \%$ [normal < 4\%]). The mean baseline FEV1 in the asthma group was $2.22 \mathrm{~L}$ (76\% predicted) with a mean FEV1/ FVC of $74 \%$. In the cough group, mean FEV1 at baseline was 2.45 L (90\% predicted) with a mean FEV1/FVC of $84 \%$.

In the asthma group there was significant improvement in mean AQLQ ( $7=$ best, $0=$ worst) from baseline of 3.29 $(\mathrm{SD}=1.1)$ to $4.38(\mathrm{SD}=1.2)$ at 3 months and $4.44(\mathrm{SD}=1.4)$ long term (Figure 1). In the cough group, cough scores $(0=$ no 